\title{
Ver después del final: Promesas naturales de Oliverio Coelho*
}

\section{Resumen}

Promesas naturales es el tercer episodio de una trilogía que Oliverio Coelho publica entre 2003 y 2006. De la misma manera que Los invertebrables y Borneo, para la construcción de lo que se propone como futuro, el último avatar de la saga tensiona el tiempo de la inmanencia de las crisis con un horizonte de final radical que lo pone en jaque. En el contexto más amplio de una investigación en torno a los imaginarios para después del final en la narrativa argentina reciente, el presente trabajo aborda la manera particular en que, a partir de esa tensión, Promesas naturales estratifica las temporalidades. Para dar cuenta de esa singularidad se analizan los modos de articulación de la visión, de la mutación biológica, de los mecanismos de control del Estado y de los límites territoriales.

Palabras clave: Narrativa argentina actual; Oliverio Coelho; Imaginarios para después del final; visión; Estado.

Citar: Catalin, M. (julio-diciembre 2018). Ver después del final: Promesas naturales deOliverio Coelho LaPalabra,(33), 17-32. doi: https://doi.org/10.19053/01218530. $\mathrm{n} 33.2018 .7975$

\section{Mariana Catalin}

Doctora en Humanidades y Artes, mención Literatura por la Universidad Nacional de Rosario. Se desempeña como Investigadora Asistente en el Consejo Nacional de Investigaciones Científicas y Técnicas y como Profesora adjunta en la cátedra Literatura Argentina I en la Universidad Nacional de Rosario.

mrianacatalin@gmail.com

*Artículo de reflexión. 


\section{la palabra}

\section{Seeing after the End: Promesas naturales [Natural Promises] by Oliverio Coelho}

\section{Abstract}

Promesas naturales is the third episode of a trilogy published by Oliverio Coelho between 2003 and 2006. As with the first two episodes, Los invertebrables and Borneo, the saga's last avatar constructs the future by tensing the immanent time of crises against a horizon of radical end that question it. In the broader context of research on post-apocalyptic imaginaries in recent Argentinian narrative, the present work analyzes the particular way in which, Promesas naturales stratifies temporalities, based on that tension. In order to account for this singularity we examine the modes of articulation of vision, biological mutation, State control mechanisms and territorial limits.

Keywords: contemporary Argentine narrative; Oliverio Coelho; post apocalyptic imaginary; vision; State.

\section{Voir au-delà de la fin: Promesas naturales [Promesses naturelles] d'Oliverio Coelho}

\section{Résumé}

Promesas naturales est le troisième épisode de la trilogie publiée par Oliverio Coelho entre 2003 et 2006. Tel que dans Los invertebrales [Les invertébrés] et Borneo [Bornéo], pour ce qui est de la construction du futur, le dernier ouvrage de la saga met en tension le temps de l'immanence des crises en proposant un horizon final radical menant à l'échec. Dans le contexte plus large d'une recherche autour des imaginaires post-apocalyptiques dans la littérature argentine récente, nous questionnons, de manière spécifique, dans le présent travail, en quoi, à partir de la mise en tension que nous venons d'évoquer, Promesas naturales, stratifie les temporalités. Afin de rendre compte de cette singularité nous analysons comment s'articulent la vision, la mutation biologique, les mécanismes de contrôle de l'Etat et les limites territoriales.

Mots-clés: littérature argentine contemporaine; Oliverio Coelho; imaginaires post-apocalyptiques; vision; Etat.

Promesas naturales es el tercer episodio de una trilogía que Oliverio Coelho publica entre el 2003 y el 2006. De la misma manera que los dos episodios anteriores, Los invertebrables y Borneo, el último avatar de la saga se construye sobre un tiempo después del final, figurando un corte radical que parece haber hecho mutar un estado previo que desconocemos. Pero, a la vez, las mutaciones que ostenta ese presente singular parecen haberse acumulado sin derivar de un núcleo común. En un artículo en el que 
analiza producciones de ficción norteamericanas de comienzos del siglo XXI, Benjamín Kunkel plantea una distinción entre las ficciones distópicas y las apocalípticas:

First, however, a distinction needs to be made between the dystopian and the apocalyptic, because these categories refer to different and even opposed futuristic scenarios. The end of the world or apocalypse typically brings about the collapse of order; dystopia, on the other hand, envisions a sinister perfection of order. In the most basic political terms, dystopia is a nightmare of authoritarian or totalitarian rule, while the end of the world is a nightmare of anarchy (Kunkel, $2008, \mathrm{~s} / \mathrm{p}$ ).

Sin duda, esta distinción puede ser complejizada, por ejemplo, desde los aportes previos reunidos por Raffaella Baccolini y Tom Moylan (2003) sobre utopía y distopía, pero también desde la proliferación de términos que registra Heather Hick (2016) en torno a lo que piensa como una nueva articulación de la novela posapocalíptica. Sin embargo, retomarla (en relación con la utilización que hace de la misma, entre otros, Silvia Kurlat Ares (2017), para abordar la ciencia ficción argentina actual) resulta interesante porque me permite recontextualizar una tensión sobre la que se sostiene Promesas naturales y los otros dos avatares de la serie: la tensión entre el tiempo de la inmanencia de las crisis que vehiculiza una lógica de la sucesión (Kermode, 1983) y un tiempo del advenimiento que lo pone en jaque al construir un gran horizonte del fin de los tiempos -que, sin embargo, se presenta como carente de mesianismo (Derrida, 1997)-. Es decir que, si se piensa desde los modos de final y no solo, aunque también, desde las geografías que se construyen posteriormente, lejos de poder ser incluida en alguna de las dos categorías, la serie se sostiene sobre la imposibilidad de la definición. Imposibilidad de definición que genera un punto de vista privilegiado para observar la manera singular en que la trilogía articula la superposición de tiempos, un rasgo predominante en la literatura mundial de anticipación de las últimas décadas (Reati en Kurlat Ares, 2012).

En este contexto, Promesas naturales pone en juego, en relación con los episodios previos, una diferencia que se vuelve fundamental: la generación de datos necesarios para optar entre la hipótesis de la catástrofe o la de la sucesión de las crisis se exacerba en función de la manera en que opera la dinámica de circulación entre el espacio interior y el afuera. Esto no supone que en el recorrido que propongo a continuación se neutralice esa tensión constitutiva: paradójicamente, saber más no asegura una elección certera. Lo que sí habilita el reconocimiento de esta torsión es una posibilidad para pensar la manera en que este avatar de la trilogía genera nuevos énfasis ${ }^{1}$. Por una parte, en función de la especificación de los territorios: la cartografía de los mismos, antes apenas esbozada, se expande y se detalla. Por otra, en relación con los espacios que se vuelven centrales: entre los espacios interiores que se narran, pasan a ocupar un lugar fundamental los públicos y colectivos en detrimento de los privados. En este contexto, la tensión que supone la coexistencia de los elementos de disciplina/ control centrados en el Estado, se articula de manera singular en torno a la visión: lo que se nos muestra, pero a la vez los modos de ver y de ser visto, marcan particularmente el funcionamiento de los espacios estatales y su relación con los afuera tolerados. Una singular articulación de los sentidos repercute así sobre la superposición de

He introducido la hipótesis de la posibilidad de generar este corte (no solo a partir de la manera en que opera la tensión entre los espacios sino también en función de la forma en que se articula la urgencia que en general tiñe los horizontes de final) y analizado los dos primeros avatares de la serie en un artículo previo [se omiten los datos en función de la evaluación]. 
temporalidades y sobre la manera en que podemos pensar se vinculan el resto y el novum tecnológico, pero también, $\mathrm{y}$ fundamentalmente, biológico.

Primera imagen: territorios y modos de mirar

Los dos episodios previos nos han dejado una serie de datos. En el presente que configura Los invertebrables, hay una división central, y esa división es geográfica. Desde el interior del lugar en el que viven, hacia el final, el personaje recuerda haber estado del "otro lado". Ni ese "otro lado" ni este lado tienen nombre. Lo único que se esboza a través del divagar de la primera persona que lleva adelante el relato, son hipótesis sobre el funcionamiento de la relación entre ambos territorios: "de este lado siempre seríamos estafados. Lo que nosotros perdíamos era el provecho de los del otro lado" (Coelho, 2003, p. 76); "hasta diría que no había vida ni evolución natural. Nos ofrecían lo necesario para que duráramos sin incomodar" (Coelho, 2003, p.100). Pero el relato de Dalila, sobre el que se sostienen muchas de estas descripciones, es puesto en duda, puede ser una fábula. Y lo que el protagonista recuerda puede no ser más que una de sus divagaciones. En Borneo, los controles a los que debe someterse Ornello, su posesión del permiso de habitabilidad y el temor a ser deportado, puede hacernos suponer que se encuentra del "otro lado". La división no se manifiesta explícitamente en los términos de la novela anterior, pero sí hay una mención de los territorios paralelos. Allí es donde el Estado destinaría a ciertos varones luego de que las mujeres espías los detectan como "sobrantes", por lo que podemos suponer que esos territorios paralelos equivalen a lo que en Los invertebrables se constituía como "este lado".

Si bien Borneo nos describe, entonces, este otro territorio, la manera de confrontar su composición mediante el énfasis en las reflexiones del protagonista, que solo dejan lugar a la materialidad mediante indicios, y a través de la tensión entre los espacios interiores privados y el exterior es muy similar al episodio previo. En este contexto, más allá de los modos de dominación específicos -que, si seguimos la lectura que realiza Gilles Deleuze (1999), superponen dos formas, las que ponen en juego el Estado de control y las que caracterizaban al Estado disciplinario tensionándose entre ambas-, la sombra del Estado se proyecta particularmente sobre las temporalidades que construyen los personajes, sobre sus modos de pensar la sucesión y la causalidad.
Promesas naturales retoma la denominación "territorios paralelos" de la segunda novela y parece, a través de ella, volver al afuera no narrado del primer episodio. Ahora bien, nos esboza un comienzo totalmente diferente a los otros dos. Incluso antes del íncipit que se constituye directamente en el afuera, sorprende la manera en que se conforma el índice. Los libros anteriores no tenían índice y sus partes iban precedidas por un número, destacándose, así, la sucesión (en relación con el eje temporal). Sucesión que en Los invertebrables partía de una anomalía: la serie empezaba en el "II", como indicando una parte previa perdida. En Promesas naturales, en cambio, los capítulos tienen nombre. $\mathrm{Y}$ tres de ellos dan cuenta de lugares: ministerios, ciudad difunta y refugio. Este detalle, que podría ser casual, se refuerza apenas damos vuelta a la página ante la aparición de un plano de los "Territorios paralelos". Las zonas que presenta el mismo están divididas en función de las especies. Consecuencia inmediata: la recolección de datos que los dos episodios previos de la serie exigía al lector, parte en este caso no del "II", no de la falta, sino de una explicitación contundente.

En diálogo con esa imagen, la contratapa enfatiza de manera singular la división en especies y "el plano" en que se moverá el personaje principal. Entonces, a 
diferencia de lo que ocurre en los otros dos episodios, se nos obliga a ver. En dos sentidos: vemos dibujos de eso que antes no veíamos, es decir, sumamos otra clase de imágenes a los grafemas; pero, además, proliferarán detalles explícitos sobre el funcionamiento de ese mundo que antes eran retaceados, ya sea por la manera en que el narrador se enfocaba en las divagaciones del personaje o por la escasa permanencia de los mismos en el territorio exterior. Este episodio, podríamos sostener, nos otorga así claridad. Sin embargo, el comienzo de la novela, que nos coloca inmediatamente en un umbral físico, empieza a complejizar ese énfasis. En el momento de la partida, Bernina "observa" el escenario de la convivencia, pero esa observación lejos de proveernos algún detalle sobre el mismo, decanta en la pregunta por cómo contabilizar el tiempo que ha pasado allí. Se produce así un cruce de los límites entre los significados y ese cruce supone un juego en torno a la facultad esperable: el verbo "observar" es utilizado claramente en relación con el matiz de ver, pero los resultados ponen en juego una observación ligada al examen no visual sino reflexivo.

Si el Estado divide claramente los espacios y recluye a cada una de las castas en un territorio; si los mapas nos hacen ver esa división; en contraposición, ciertos modos de articulación de la narración ponen en jaque el correcto funcionamiento de los límites al generar un cruce de los territorios semánticos $\mathrm{y}$ fundamentalmente, al pervertir el funcionamiento (esperable) de la vista. Y esto puede pensarse en relación con la mutación de las especies. Entre una de esas mutaciones se encuentra la pérdida del habla. Cuando se la describe no solo se menciona entre las causas su olvido, sino también ciertos cambios físicos que la imposibilitan ${ }^{2}$. En esta línea, el funcionamiento del sentido de la vista es acechado por un mismo interrogante. Si bien la novela no hace mención explícita de una mutación, tematiza el problema de diversas maneras $\mathrm{y}$, a la vez, la composición de algunas descripciones aparece enrarecida (en ciertos casos apelando a una construcción metafórica que desplaza la adjetivación esperable). ¿Ha mutado el funcionamiento de ese sentido? ¿esa mutación habilita una forma de resistencia?

Contrastemos el plano que nos presenta la novela y las descripciones que se nos brindan del exterior en el primer capítulo. Obviamente, como todo plano, el que se nos ofrece de los territorios paralelos, proporciona una visión esquemática y a escala que recala fundamentalmente en el orden estructural, algo que la visión de un solo sujeto ubicado dentro del mismo no podría reproducir. Pero incluso más allá de esa prevención, la descripción que Bernina nos hace de ese espacio exterior lo enrarece. Por una parte, en contraposiciónal espacio urbano abigarrado que se nos muestra en el plano, las descripciones enfatizan lo descampado y lo desértico (justo aquello que el

$2 \quad$ Tanto Reati (en Kurlat Ares 2012) como Isabel Quintana (en Kurlat Ares 2012) y María Semilla Durán (2014) han puesto el énfasis en estas mutaciones. El excelente abordaje de Semilla Durán destaca la relación con el Estado como ente disciplinador, dando cuenta de la separación en castas biológicas y de la reclusión territorial. En relación con esto, me gustaría señalar dos cosas. Por una parte, recordar que en los episodios previos las mutaciones se constituyen en la manera en que los personajes escapan del control/disciplinamiento del Estado. Por otra, el acercamiento de Semilla Durán insiste en un modo de lectura que relaciona con la alegoría. Al definir al monstruo como producto intersticial, destaca que las formas de esa contaminación "parecieran organizarse para proponer una representación alegórica de ciertas prácticas sociales y políticas vigentes en el mundo" (Semilla Durán, 2014, s/p). Ante esto, quisiera retomar las consideraciones de Gabriel Giorgi (2009), quien destaca que el monstruo porta dos tipos de saber. El primero, en línea con lo propuesto por Semilla Durán, se relaciona con la puesta en escena de las ansiedades, repudios y fascinaciones que atraviesan la imaginación social. Pero, a la vez, el monstruo porta un saber positivo: "el de potencia o capacidad de variación de los cuerpos, lo que en el cuerpo desafía su inteligibilidad misma como miembro de una especie, de un género, de una clase" (Giorgi, 2009, p. 323). Mi lectura, cuando se detenga ante estas mutaciones, tratará de sostener ese umbral de desconocimiento, enfatizar la potencia de variación como modo de exploración y experimentación. 
plano no puede mostrar más que como vacío). A esto se suma el hecho de que cuando la protagonista tiene que dar cuenta del "tejido de ruinas urbanas" lo hace mediante la mención de elementos, detalles, que se presentan de manera acumulativa, fragmentando la perspectiva. Además, recala singularmente en los tonos de la luz que, lejos de mostrar directamente, habilitan el desplazamiento metafórico: "El sol apenas retenía un manojo fruncido de colores. En torno el paisaje mutaba, bloques de salivosa porcelana se derramaban hacia el anochecer" (Coelho, 2006, p. 29). Los modos de mirar de Bernina, que parecen así acumular fragmentos y colores antes que articular una perspectiva que permita ubicar los objeto en un espacio homogéneo $\mathrm{y}$ regularmente ordenado, dan lugar a una singular cartografía de la materialidad que se tensiona con la propuesta por el plano, que apela a la misma como búsqueda activa de control y dominación de un espacio.

Pero, además, todo el primer capítulo (y luego, el resto de la novela) tematiza insistentemente la cuestión de la experiencia visual y la hace proliferar en diversos sentidos. Martin Jay (2007), al dar cuenta del papel hegemónico de la visión en la cultura occidental moderna, destaca la multiplicidad de matices que se ponen en juego cuando se convoca la experiencia visual. $\mathrm{Su}$ recorrido permite reparar en la variedad de fenómenos ópticos, perceptivos y mentales que convoca la "visión" y cómo los mismos se tensionan en cada régimen escópico afectando desde las maneras de pensar las relaciones entre el sujeto y el objeto, hasta los modos de articulación del poder y el vínculo con los otros (entre la fantasía paranoide de estar bajo una vigilancia continua $y$ hostil, y la excitación narcisista del exhibicionista). Desde las reflexiones de Jay, la manera en que Promesas naturales torsiona el régimen escópico mediante una multiplicación que parece sacarlo de eje, se vuelve evidente. En el primer capítulo, en relación con las mutaciones de las especies, no solo se destaca que la mirada de los Ilotas convierte a Bernina en imagen y así en objeto de deseo o que la vista y el olfato de los niños desnudos de las zonas más apartadas le proporcionan informaciones contradictorias, sino también la posibilidad de existencia del Guru ñatito de un solo ojo. Cíclope que, según la creencia mística y popular, podría enfocar más allá. Además, en la presentación del niño cojo se destacan los instrumentos de visión que ha desarrollado para la cacería, sosteniéndose luego, en un desplazamiento metafórico paradigmático ya que queda en el borde de la efectivización, que cuando disciplinara la práctica podría auscultar a la víctima desde la astucia.

La visión es, también, central en la articulación del problema de la memoria ya que el pasado reaparece en imágenes, que se presentan como retratos, pero borroneados. En lo que refiere específicamente al Estado, su presión se presenta como "transparente", apelando a la idea del ojo que todo lo ve sin que sea necesario que se manifieste en controles precisos. Incluso, la corporalidad de Bernina es afectada. Aquello que no se ve, Odiseo, se convierte en un momento en "un ojo que amortizaba su potencia desde la desaparición, la fuga de la sustancia" (Coelho, 2006, p. 24). Si uno de los objetivos de la huida es la posibilidad del parto, la constante mención del mismo a través de sus sinónimos (alumbramiento, dar a luz) permitiría sostener que Bernina no es simplemente vista, no solo ve, sino que también quiere dar a ver, como de hecho lo hace al final. En este contexto, es el espejismo lo que permite explícitamente poner en jaque los límites:

La costra de los niños estaba intacta. Y sobre esa costra, aglomeraciones de realidad desplazando la escoria hacia un espejismo que se paralizaba, igual a un ave de mal agüero, en un límite: una orilla que en vez de definir pare- 
cía borrar territorios, engullir objetos y devolverlos trasmutados al paisaje (Coelho, 2006, p. 16).

Estamos obligados a ver el plano y, además, la novela recala en la descripción visual de las especies como nunca antes y como con ningún otro objeto, poniendo en juego el poder clasificador de la mirada. Pero, a la vez, se hace proliferar el tópico hasta enloquecerlo y justamente sobre uno de los rasgos de la especie se genera el espejismo que, si bien es un "ave de mal agüero", hace emerger una orilla que permite borrar la delimitación territorial.

\section{Segunda imagen: ministerio y panóptico}

$\mathrm{Si}$ las especies recluidas son mostradas insistentemente, otro es el caso de lo que ocurre ante la aparición de los funcionarios. Cuando la capturan por primera vez, Bernina decide no dirigirles la mirada. Sus primeras apreciaciones recalan entonces en su olor, en sus voces que "rezumaban ese tipo de ternura que anticipa la sed" (Coelho, 2006, p. 32). Pero, este modo de articulación de la descripción no se modifica sustancialmente cuando finalmente los enfrenta con la vista: al dar cuenta de su rostro, las bocas son solo calificadas como golosas y los rasgos como opacos. Lo mismo sucede con los habitantes del otro lado: si en la confrontación se enfatiza el sentido de la vista, cuando se los califique solo sabremos que son diligentes y discretos. Hay, como puede observarse, indicios de un posible uso metafórico, pero el mismo parece no poder dar cuenta enteramente de esta forma de percepción: el juego transforma al Ministro, al "anular el sentido de sus atributos físicos", "en un ser superior: un animal en la bancarrota del sentido" (Coelho, 2006, p. 47).

Es imposible determinar si la abstracción, en tanto característica que la narración destaca como propia de la protagonista, es lo que habilita esta forma de percepción o si es una mutación en el sentido de la vista la que genera esa tendencia. Lo que sí sabemos es que, en este caso, el desplazamiento reproduce la jerarquía del ocultamiento (el poder de no ser visto), pero, a la vez, deja presos a los funcionarios de los modos de ver de la protagonista, marcados por la circulación de su deseo que articula un ordenamiento singular.

En esta proliferación de referencias a la experiencia visual, hay una escena central para pensar las formas de circulación del poder en relación con el Estado. En el Ministerio, Bernina accede a un lugar que se describe de la siguiente manera: "Levantó la vista y vio a unos pasos una especie de balcón mirador que parecía dar a una fosa. Se le ocurrió que podía tratarse de un panóptico y que debajo debían recrearse los presidarios" (Coelho, 2006, p. 46). La suposición de Bernina queda avalada por lo que el plano previo, en su corte longitudinal, parecía haber puesto en juego. Sabemos ya que Foucault, en Vigilar y Castigar (2009), cifraba en el panóptico los modos de funcionamiento del estado disciplinario moderno. En la clásica entrevista que, a propósito de las hipótesis expuestas en torno a ese tema, le realizan Jean-Pierre Barou y Michelle Perrot, hay un fragmento que si bien ha sido frecuentemente citado me gustaría retomar. El mismo expone claramente el modo en que se complementan el disciplinamiento efectivo $\mathrm{y}$ el poder profiláctico de la vigilancia en torno al papel de la mirada: "Basta una mirada. Una mirada que vigile, y que cada uno, sintiéndola pesar sobre sí, termine por interiorizarla hasta el punto de vigilarse a sí mismo; cada uno ejercerá esta vigilancia sobre y contra sí mismo. ¡Fórmula maravillosa: un poder continuo y de un coste, en último término, ridículo!" (Barou, 1980, p. 18). Ahora bien, también sabemos que Deleuze, en "Postscriptum sobre las sociedades de control" (1999), sostenía que en la actualidad se estaría 
produciendo un pasaje de esas sociedades disciplinarias a las sociedades de control.

Al abordar ese cambio en el modo de la vigilancia, Jay (2007), nos dice que las hipótesis de Deleuze ponen en el centro un pasaje de lo visual a lo informático. Pero antes que un desplazamiento en ese sentido, podríamos sostener que lo que Deleuze hace es colocar el énfasis en uno de los aspectos supuestos en el panóptico como dispositivo (el espacial, al sostener la caducidad de los encierros) sin hacer mención explícita del otro polo de la relación (el lugar de la visión). Desde otro punto de vista, el énfasis de Bauman (2002) es similar, ya que vuelve a marcar el cambio en función de la territorialidad al destacar la capacidad de movilidad actual del poder. $\mathrm{Si}$, en este contexto, retomamos acercamientos como los de Poster (1995) y su concepto de "super-panóptico" o los de Lyon (1995) y su "ojo electrónico"; o bien los del propio Bauman -en su primera opción por el sinóptico (2001), pero fundamentalmente en la complejización de sus hipótesis en el diálogo posterior con Lyon (2013)-y los de Wajcman (2011) y su reflexión en torno a las nuevas configuraciones de las exigencias de visibilidad, podemos sostener que antes que desplazar la visualidad lo que se busca es repensar, después de la centralidad del panóptico, la relación entre la misma, las nuevas tecnologías y la vigilancia/seguridad redefiniendo sus alcances e implicancias.

Promesas naturales introduce, entonces, la posibilidad de existencia de un panóptico $\mathrm{y}$, esto es fundamental, la especifica en su concreción arquitectónica precisa. Como si esto fuera poco, una de las cuatro imágenes que incluye el libro parece avalar su existencia. Pero esta expectativa es decepcionada. Cuando Bernina se acerca al mirador, lo que observa no son celdas vigiladas desde una torre central. Debajo de ella solo hay una cancha cubierta en la que el Ministro y sus dos hijos juegan a la pelota paleta.

Se tensiona así la relación entre el ver y el ser visto, entre la disciplina y el control: el espacio que en el Ministerio se podría leer en la lógica de la relación necesaria entre encierro y visibilidad, es insinuado y luego impugnado. Este episodio condensa así las temporalidades superpuestas que se articulan a través de los diversos mecanismos de vigilancia y control, y la particular relación de los mismos con los modos de ver y de configurar los espacios y territorios. Por un lado, Bernina de hecho parte de un encierro preciso y es siempre recapturada. Y la novela no hace ostentación de nuevas tecnologías de control visual que pudieran haber reemplazado la del panóptico y habilitado otras lógicas de control. Pero, a la vez, esos encierros son lábiles, la protagonista puede moverse de un espacio a otro con relativa facilidad. $Y$ se mencionan otros desarrollos tecnológicos y científicos que impugnan una hipótesis regresiva total. La presión del Estado se ejerce a través de los controles específicos, pero también, de manera "transparente", parece manifestarse omnipresente. Y si esa omnipresencia puede entenderse en ciertos momentos como una introyección de las lógicas de disciplinamiento, a la vez el secretario del segundo Ministro con el que se encuentra Bernina posee un informe detallado de sus movimientos; informe que no parece obedecer solo a la lógica clásica del espionaje, sino que deja al lector con la incertidumbre sobre los medios que se han utilizado para obtenerlo.

Pero hay una precisión más. En el momento en que Bernina es cargada por Chatran, se describe el exterior de la siguiente manera: "Los paisajes, si bien soportaban texturas y olores bastante delicados, no asombraban por su complejidad sino por la forma de su secuencia: una misma imagen repetida y encadenada al infinito" (Coelho, 2006, p. 65). Esta afirmación podría leerse, sin duda, en relación con 
los desarrollos de Baudrillard $(1978,1994)$ en torno a la idea de simulacro. La manera en que funciona el encadenamiento de imágenes y el lugar ambiguo que se le otorga al espejismo, podrían permitirnos pensar en un mundo articulado por la simulación que ha desplazado ya la "magia de la representación" y que ha vuelto inútil la idea de espectáculo para comprenderlo. Sin embargo, el juego con esta posibilidad parece similar al que se realiza con el panóptico: se plantea y se desarma.

Antes que proponer una realidad simulacral, la novela tensiona los modos de percepción en relación con los sentidos. Cuando Bernina se encuentra con el segundo Ministro, lo que él destaca como ligado al poder es la capacidad de escuchar. Esa escucha se relaciona con formas "tradicionales" de la actividad de espionaje. Pero, a la vez, al igual que con el registro de la historia de la protagonista, se desplaza esa posibilidad. Por una parte, se la liga, en el borde de la metáfora, específicamente a una cualidad física del Ministro: su oído es presentado como un "músculo aspiradora", un "tímpano insaciable" (Coelho, 2006, p. 95). Por otra, se la relaciona con el desciframiento de los lenguajes atmosféricos que están lejos de ser formas de codificación para ocultar una información específica, vinculándose, antes bien, con una dimensión metafísica y, nuevamente, con una mutación de la especie, pero propia de los habitantes de los territorios paralelos.

Lo particular es que, en ambos casos, esa posible mutación no es presentada ni como falta ni como deformación, lo que desarma la lógica lineal de la evolución/involución. Es difícil, entonces, pensar los modos en que se construye el control y la vigilancia como prolongación exasperada de ciertas características del presente. Y la causalidad de la referencia se enrarece aún más al cifrar esa posibilidad de anticipación en formas de relación pasadas y canceladas entre Estado $\mathrm{y}$ totalitarismo, pero que se muestran, sin embargo, como parcialmente realizadas. A la vez, la hipótesis regresiva total es obturada por el modo en que se articula el novum biológico. La acumulación de los restos genera una lógica extrañada que no parece ser simplemente la de los estratos coexistentes. La pregunta se vuelve, entonces, ineludible: ¿cuál es el tiempo de esta serie?

\section{Tercera imagen: el refugio}

Los otros dos planos o dibujos que nos presenta la novela, entablan una relación de referencia con otro espacio central: el refugio. El contacto con lo que se narra vuelve a ser conflictivo, con la particularidad de que el conflicto en este caso parece querer ponerse de manifiesto. El "CORTE TRANSVERSAL DEL REFUGIO" se coloca inmediatamente al lado de la descripción que el Ministro hace de ese espacio. Pero la imagen, si bien refleja la disposición vertical que analiza la descripción, no muestra un rasgo sobre el que el personaje insiste: las dos líneas, una perteneciente a cada territorio, que se cortan en un punto. Se exacerba así el conflicto entre lo que se nos muestra y los modos de ver de los personajes justamente en la definición de los límites. La misión de Bernina será infiltrarse en el refugio. Y una de sus tareas específicas, trazar justamente un plano. Un objetivo difícil de alcanzar si tenemos en cuenta la manera en que se ha articulado la cartografía previa y el modo en que se ha manifestado su tendencia a la abstracción, que antes que esquemas produce desplazamientos metafóricos.

Sin embargo, jugando nuevamente en torno a las relaciones entre cartografía y poder, el ingreso de la protagonista a uno de esos territorios diagonales tensionará esa imposibilidad. El relato dará cuenta de algo del recorrido, reconociendo pasadizos y delimitando espacios geométricamente, brindándonos la posibilidad de intentar un croquis. Pero, este primer esbozo se desgranará 
en los listados de cosas que va encontrando y acumulando Bernina. Esa fragmentación culminará con la emergencia de un modo singular de visión, que exige ser nombrado a través de una fórmula oximorónica: "perspectiva multicolor". Este tipo de perspectiva no produce un espacio racional, constante y homogéneo, sino que, sosteniendo una mirada que parece no tocar fondo, hace que la misma se unte de colores y ponga en jaque ciertos mecanismos de la lógica, favoreciendo, además, la percepción del movimiento como cíclico antes que como lineal.

Cuando Semilla Durán analiza el carácter contra-utópico de Promesas naturales, lee el refugio como un posible espacio alternativo, como el "Paraíso de los resistentes" por el modo en que se da la convivencia entre las diferentes especies; una "coherencia en la deformidad" que obstaculiza el cumplimiento de los objetivos del Estado. El texto mismo, en un nivel autorreflexivo, sostiene esa lectura al presentarlos como "nudos de felicidad"; además su organización parece haber "resucitado, como los espejismos, lo humano de lo humano" (Coelho, 2006, p. 117).

Ahora bien, las escenas de visión que se nos presentan parecen, en cambio, mostrar otros matices del funcionamiento de esa comunidad y del vínculo de la misma con los mecanismos que se han presentado como estatales. En primer lugar, en relación con el modo en que es expuesta Bernina a la vista de los otros. En el refugio la protagonista vuelve a ser atada a una camilla convirtiéndose, esta vez, en objeto de observación. Nuevamente es, entonces, vista e inmovilizada. Es cierto que, en esa exposición, a la manera en que lo habilitan las mutaciones biológicas, los límites entre los territorios asignados a las diferentes prácticas se desdibujan: lo que padece la protagonista relaciona revisación médica y espectáculo de magia.

La narración no nos deja entrever si lo que Bernina es obligada a transitar surge de la mezcla entre medicina $y$ magia o es, en realidad, una práctica nueva de la que ella solo puede dar cuenta cruzando los referentes de esos modos de hacer previos (detectando en el interior del médico al mago y llamándolo, luego, maestro). Ahora bien, esta singular articulación de la que se intenta dar cuenta, lejos de sostenerse en ese cruce, culmina con un efectivo examen: "ese dudoso hombre de ciencia auscultó rápidamente a Bernina, la midió con todo tipo de varas auxiliares [...] examinó su piel, sopesó sus mamas alternativamente" (Coelho, 2006, p. 132).
Y sabemos ya, desde los desarrollos de Foucault (2009) y tal como lo destaca Jay (2007), que la mirada médica y la mirada de la vigilancia están intensamente relacionadas.

Detengámonos, entonces, en la cuarta imagen. La misma parece volver a poner en juego la idea de panóptico. Pero, esta vez, la narración en vez de decepcionarla, la confirma, al menos parcialmente. Bernina, luego del examen, es llevada a una celda. Si bien la disposición en la que la misma se incluye no es estrictamente panóptica, sí es caracterizada, a diferencia de los encierros previos, por la visibilidad que articula: “[...] ahora no había muros. Si asomaba la cabeza entre los finos barrotes tenía una perspectiva despejada del sitio: jaulas que parecían exponenciadas por la abundancia de barrotes y cerrojos" (Coelho, 2006, p. 135). Esas celdas son el modo de aislar lo inclasificable (dentro de lo inclasificable) $\mathrm{y}$, además, la antesala a una nueva distribución en territorios. Todos pueden verse, tener esa visión en perspectiva que ahora Bernina también posee y son también sometidos a la espera. Ese modo de disciplinamiento actúa sinérgicamente con otra forma de control que se articula a través del chisme y la envidia. Forma de control que se relaciona con el género y los estereotipos heteropatriarcales que delimitan ciertos 
comportamientos asociándolos a lo femenino, un problema que recorre toda la novela. Es a partir del comportamiento de las bambilamborghinianas y su relación con el de Curone y Letita, que Bernina realiza el paralelo con el funcionamiento del Ministerio descubriendo, entre este y el refugio, "una simetría escalofriante" (Coelho, 2006, p. 142).

En esta línea, el refugio es, también, donde se efectiviza eso que la novela ha planteado de manera problemática, pero hasta este momento solo como posibilidad: la salvación femenina vehiculizada por una figura masculina. El Ministro le había ofrecido salvarla. El hechicero efectivamente la salva. Es en esos términos en que se plantea la salida de Bernina de ese espacio ${ }^{3}$. Y es solo a través de su salvador que se le habilitará la posibilidad de representar, mediante un teatro de títeres y ya en el final, su propia historia.

El refugio se presenta así, como un punto de tensión, nuevamente, entre los sentidos. Cabe retomar entonces la explicitación, ese "resucitar lo humano de lo humano". En el ingreso a este territorio, esa resurrección se relaciona con la pérdida, no del lenguaje, sino del habla articulada. Es esa pérdida la que permite escapar al lenguaje desértico de la burocracia, sosteniendo la arquitectura del refugio. Pero, la exploración que realizará Bernina de ese espacio irá desarmando esa imagen inicial. Por una parte, la única manera de pertenecer a esa comunidad, en el caso de la protagonista, sería la "emasculación oral". Es nuevamente necesario obtener algo que la selección natural no ha brindado para poder así "triturar el espejismo, librarse de ese plasma de astillas que flotaban en la lengua" (Coelho, 2006, p. 128). La "selección natural" actúa entonces en ambos frentes, enrareciendo las relaciones entre lo que se presenta como involutivo y evolutivo. Pero, además, la falta de habla articulada como sostén comunitario no solo no está a salvo del oído biológicamente modificado del Ministro (que descifra lenguajes atmosféricos), sino que tampoco impide que Bernina sea convertida en espectáculo y sometida a un modo de vigilancia en el que no deja de ser vista. Y es en esa prisión en la que ese sostén se muestra como mero artificio, ya que las compañeras de celda de Bernina, de hecho, hablan. Y es ese hablar el que permite sostener el chisme, pero también la explicitación de la diferencia en negativo: "Nosotras las hipocentaurinas somos segregadas. Tanto que ya somos incapaces de amar" (p. 145). ¿Cuál es, entonces, el sentido del (que genera el) "espejismo"?

\section{Redistribuciones}

Sabemos sobradamente que las periodizaciones históricas, si no arbitrarias, sí son construidas. Teniendo siempre en cuenta esta prevención, podríamos sostener que la intervención de Josefina Ludmer entre finales del 2006 y comienzos del 2007 , se constituyó como un mojón para aquellos que estudiamos literatura argentina actual, el cual abrió una discusión intensa sobre las maneras de dar cuenta de la singularidad de las prácticas literarias del presente. La figura del final, a través del discutido prefijo "pos" que Ludmer había puesto en juego, y que habilitó defensores y detractores, fue central. ¿Estábamos frente al reemplazo de un sistema por otro o ante un verdadero cambio de paradigma? La discusión se nutrió con la puesta en juego de ciertos aportes teóricos de la filosofía más reciente, fundamentalmente las

3 La escena es contundente y pone en juego un término, "espejismo", en el que veremos se concentra el conflicto de este territorio: "Señaló a Bernina y en cuanto ella se puso de pie y salió de la jaula caminado, un suspiro de envidia recorrió la atmósfera del presidio. Ella tuvo la impresión de que desde todos los costados murmuraban su nombre. El bullicio aumentaba; los "oh, oh, oh, pol favol, pol favol, pol favol" encapotaban la atmósfera, abrían el espejismo de un calvario mientras los prometidos se alejaban [...]" (Coelho, 2006, p. 153). 
problematizaciones en torno a lo "contemporáneo" de Giorgio Agamben (2010), las reflexiones sobre la idea de "aura" y las formas de supervivencia de George Didi-Huberman (2006, 2009) y el debate sobre los alcances del "régimen estético" de Jaques Rancière (2009), siempre generando usos $\mathrm{y}$ puntos de vista singulares. En la "Presentación" al dossier "Ficciones en transición", Sandra Contreras, al dar cuenta de las versiones más recientes de estas discusiones, propone un modo singular de abordar lo particular de esta coyuntura. Retomando la interrogación sobre por qué se desea tanto identificar un nuevo imaginario de las artes verbales, Contreras genera una nueva pregunta que desplaza el énfasis de la necesidad de reconocer positivamente un cambio: "¿qué deseamos o qué no deseamos ver cuando describimos los modos del arte contemporáneo como arte inespecífico, ficciones en transición o literaturas postautónomas?" (2016, p. 49). Se trata, entonces, no de adscribir sino de modular las preguntas desde la temporalidad singular que se elige y desde los modos en que, dentro de esta, se hipotetizan los cambios y los cortes.

Promesas naturales se publica el mismo año que Ludmer pone en juego sus hipótesis críticas. Obviamente, la novela no forma parte de su corpus. Ninguna de las lecturas críticas posteriores la ponen en contacto con estas discusiones. La relación es antes bien con la serie histórica, ya que tanto Reati (Kurlat Ares 2012), como Semilla Duran (2014) y Annelies Oeyen (2011), enfatizan una lectura con rasgos alegóricos. Dichas relaciones se sostienen sobre dos configuraciones de problemas: la que se articula en torno a la dictadura cívico eclesiástico militar argentina y la que lo hace alrededor de la crisis del 2001. La conclusión del artículo de Semilla Durán creo que es paradigmática: "[la novela se constituye como] una construcción apocalíptica en la que se inscriben las huellas de la crisis del sentido producida por la dictadura y las de la desagregación social operada por la crisis del 2001" (Semilla Durán, 2014, s/p). Mi intento en este abordaje, y en el que he realizado previamente sobre los otros episodios de la trilogía fue, sin desatender esas lecturas, pensar la serie en la temporalidad que pone en el centro la discusión en torno a las posibilidades del arte y de la literatura hoy. Leída desde este punto de vista, la relación con uno u otro referente alegórico no es indiferente, pone en juego temporalidades distintas. Este episodio, por el desarrollo que hace de este mundo futuro (en el que lo que estaba en potencia en los episodios previos se efectúa a través de la explicitación), me obligó a repensar esa relación. El modo en que se articulan las prácticas de visión relacionadas con los modos de disciplinamiento/control y espionaje, deja ver que la temporalidad del Estado debe sostenerse en suspenso, y que ese suspenso tensiona prácticas previas con prácticas que pueden pensarse como actuales. Una tensión que no parece jugarse en la supervivencia del resto anacrónico, ni en la idea de anticipación propia de la ciencia ficción.

Esta tensión se enfatiza de manera singular al hacer eje en las imágenes que incluye la novela. En una primera instancia, las mismas pueden pensarse como ilustrativas: el lector ve eso que antes no veía. Pero si nos detenemos en las relaciones con el texto escrito, los diferentes planos habilitan una conflictividad singular. No solo en función de la puesta en duda de lo que se narra (y viceversa, de lo que la imagen muestra y, por lo tanto, de su capacidad para mostrar), sino también, en función de la constitución de una articulación particular en la lógica de suposición-decepción que la narración habilita, uno de los mecanismos centrales que obliga a mantener en suspenso la temporalidad del Estado. Pero volvamos sobre la primera imagen. Para volver es necesario recordar, en función de la constelación de problemas que me interroga, que uno de los ejes a través del que se intenta dar cuenta de los modos específicos de la práctica 
literaria actual es, justamente, la apertura de sus límites hacia otras prácticas artísticas ${ }^{4}$. El plano con el que se abre Promesas naturales, según lo destaca Oeyen, está construido mediante la mitad reflejada de una imagen aérea de la ciudad de Venecia. Se introduce así, antes del íncipit, el problema del reflejo y el espejismo que, como analicé, se volverá central a lo largo de la novela. Pero, a la vez, la imagen está intervenida. No solo por los diversos epígrafes que la relacionan con el texto, sino también por unas líneas que parecen delimitar el espacio asignado a cada casta. La intervención, por una parte, enfatiza así el papel del mapa como dispositivo de poder.

En esta línea, si se observa el dibujo con detenimiento, se puede destacar que esas marcas que se sobreimprimen no se corresponden con ningún accidente geográfico o construcción delimitante, lo que muestra su arbitrariedad, pero a la vez la imprecisión que puede habilitar el intercambio. Ahora bien, el pensar en términos de intervención me permite generar una conexión con un episodio previo de la serie: la "intervención" (así la menciona la novela) que realiza Ornello sobre el Cristo en Borneo.
En su única salida al exterior, Ornello encuentra una reproducción de Cristo. La lleva a su casa y lejos de dejarla simplemente como adorno decide trabajar sobre ella. Esa escena adquiere un carácter muy singular dentro de la trilogía. No es que la serie no se haya ocupado en otros momentos de las formas del arte en ese tiempo que suponemos como futuro. De hecho, tanto el canto (que es lo que puede hacer el narrador antes de convertirse en perro en $L o s$ invertebrables, pero también lo que Ornello descubre en su segundo encierro como característica propia) como la danza (asociada a las mujeres) han adquirido un lugar central. Pero, ambas prácticas ponen en juego un tipo singular de belleza. La misma está relacionada con un fin específico: seducir. Su valor reside en eso, lo que supone una articulación particular en el constante contacto entre humano y animal que la serie propicia, ya que se apela a un rasgo zoológico sin convertirlo en un zoomorfismo. A la vez, ambas prácticas están relacionadas con formas de huida del control y la disciplina del Estado.

En este contexto, la intervención de Ornello se vuelve singular porque es a partir de la misma que se reflexiona espe- cíficamente sobre las potencias del arte 5 . Y porque lo único que proporciona es una "experiencia". Ornello opera por sustracción: borra algunas partes, extirpa otras $y$, finalmente, parte inesperadamente el maniquí. Es en ese momento en el que se genera la verdadera obra: el protagonista dispone los restos de yeso en un lugar privilegiado del salón, dándose cuenta, a través de ese movimiento, de que la intervención ha sido un éxito. La narración nos explicita el por qué (casi al nivel de un texto curatorial):

[...] había operado sobre una apariencia entera y no sobre una parte, y había dado a luz otro cuerpo, había parido una totalidad dividida, y una disciplina única, el canibalismo formal. El futuro desvencijado del arte... [...] La verdadera escultura acababa de ocurrir. Ornello, de un golpe de suerte, la había acabado y había rellenado las imprecisiones -el horroroso taparrabo, la barba- con la dimensión conceptual de un acto que era la superación de la obra, su inversión: la etapa carnívora en la que el arte se autodevora y pare simultáneamente su propio futuro (Coelho, 2006, p. 65).

Si el tercer avatar de la saga no existiera, más allá de la fuer-

4 Pienso en desarrollos como los de Florencia Garramuño (2015) y su idea de "arte inespecífico" o bien en los de Reinaldo Laddaga (2007) y sus "espectáculos de realidad", entre muchos otros.

5 El teatro de títeres, en cambio, pone el énfasis en el problema de la representación dentro de la representación ligado a la reflexión sobre la memoria; y lo escrito, a través de la Enciclopedia, aparece fundamentalmente relacionado con la posibilidad de saber. 
za que adquiere este episodio, el mismo sería solo eso: una imagen de lo posible. Pero Promesas naturales pone en acto lo que en el avatar previo era, justamente, solo conceptual. Opera sobre una apariencia entera, la divide y luego, como si sumara nuevas etapas al proceso, la espeja y le suma líneas. Una obra. Se tensionan así las formas de futuridad, un tiempo que se presenta como complejo pero que, a la vez, requiere de la linealidad, de la sucesión, de la trilogía.

La serie de Coelho permite así, invirtiendo ahora el movimiento, interrogar los modos de apertura o de indistinción propuestos como líneas centrales para caracterizar las prácticas de escritura actuales. Y lo hace desde textos que se presentan netamente como ficción, novela, literatura: representando, pero a la vez poniendo en práctica, una forma singular de intervención e imaginando modos de circulación del poder (relacionados con las definiciones territoriales, las formas de disciplina/control y las imposiciones/posibilidades biopolíticas) que habilitan y, a la vez, suspende la lógica del resto en función de una forma singular de estratificación de temporalidades, no solo realizadas sino también propuestas y canceladas.

\section{Referencias}

Agamben, G. (2010). ¿Qué es lo contemporáneo? Otra parte, (20), 77-80.

Baccolini, R. y Moylan, T. (ed.) (2003). Dark Horizons. Science Fiction and the Dystopian Imagination. New York: Routledge.

Barou, J. P. y Perrot, M. (1980). El ojo del poder. Entrevista con Michel Foucault. En J. Bentham. El panóptico (J. Varela y F. Álvarez-Uría, trad.) (pp. 9-26). Barcelona: La Piqueta.

Baudrillard, J. (1978). Cultura y simulacro. (P. Robira, trad.) Barcelona: Editorial Kairos.

Baudrillard, J. (1994). Simulacra and Science Fiction. En Simulacra and Simulation (pp. 121-128). Michigan: The University Michigan Press.

Bauman, Z. (2001). La globalización. Consecuencias humanas. Ciudad de México: FCE.

Bauman, Z. (2002). Modernidad líquida. (M. Rosenberg, trad.). Buenos Aires: FCE.

Bauman, Z. y Lyon, D. (2013). Vigilancia líquida. (A. Capel, trad.). Buenos Aires: Paidós.

Coelho, O. (2003). Los invertebrables. Rosario: Beatriz Viterbo.

Coelho, O. (2004). Borneo. Buenos Aires: El cuenco de plata.

Coelho, O. (2006). Promesas naturales. Buenos Aires: Norma. 
Contreras, S. (2016). Presentación. Cuadernos de literatura, XX(40), 45-55.

Deleuze, G. (1999). Conversaciones. 1972-1990. (J.L. Pardo, trad.). Valencia: Pre-Textos.

Derrida, J. (1997). Mal de archivo. (P. Vidarte, trad.). Madrid: Editorial Trotta.

Didi-Huberman, G. (2006). Ante el tiempo. (O. Oviedo, trad.). Buenos Aires: Adriana Hidalgo.

Didi-Huberman, G. (2009). La imagen superviviente. (J. Calatrava, trad.). Madrid: Abada Ed.

Garramuño, F. (2015). Mundos en común. Buenos Aires: FCE.

Giorgi, G. (2009). Política del monstruo. Revista Iberoamericana, LXXV(227), 323-329.

Hicks, H. J. (2016). The Post-Apocalyptic Novel in the Twenty-First Century: Modernity Beyond Salvage. Basingstoke, Hampshire: Palgrave Macmillan.

Jay, M. (2007). Ojos abatidos. La denigración de la visión en el pensamiento francés del siglo XX. Madrid: Ediciones Akal.

Foucault, M. (2009). Vigilar y castigar. (A. Garzón de Camino, trad.). México: Siglo XXI.

Kermode, F. (1983). El sentido de un final. (L. Moreno de Sáenz, trad.). Barcelona: Gedisa.

Kunkel, B. (2008). Dystopia and the end of Politics. En Dissent. Recuperado el 26 de abril de: http:// www.dissentmagazine.org/article/dystopia-and-the-end-of-politics

Kurlat Ares, S. (coord.) (2012). Dossier: La ciencia-ficción en América Latina: entre la mitología experimental y lo que vendrá. Revista iberoamericana, LXXVIII(238-239), 15-439.

Kurlat Ares, S. (2017). Dossier: La ciencia ficción en América Latina. Revista iberoamericana, LXXXIII(259-260), 255-671.

Laddaga, R. (2007). Espectáculos de realidad. Rosario: Beatriz Viterbo Editora.

Lyon, D. (1995). El ojo electrónico. (J. Alborez, trad.). Buenos Aires: Alianza.

Oeyen, A. (2011). Ciudades posapocalípticas en la literatura prospectiva de la Argentina posdictatorial. Ángulo Recto, 3(2), 225-245.

Poster, M. (1995). The Second Media Age. Cambridge: Polity Press.

Rancière, J. (2009). El reparto de lo sensible. (C. Durán et al., trad.). Santiago: LOM Ediciones. 
Semilla Durán, M. (2014). Monstruos, mutantes y contra-gestación: Promesas naturales, de Oliverio Coelho. Amerika (11). Recuperado el 26 de abril de 2018 de: http://journals.openedition.org/ amerika/5214

Wajcman, G. (2011). El ojo absoluto. (I. Agoff, trad.). Buenos Aires: Manantial. 